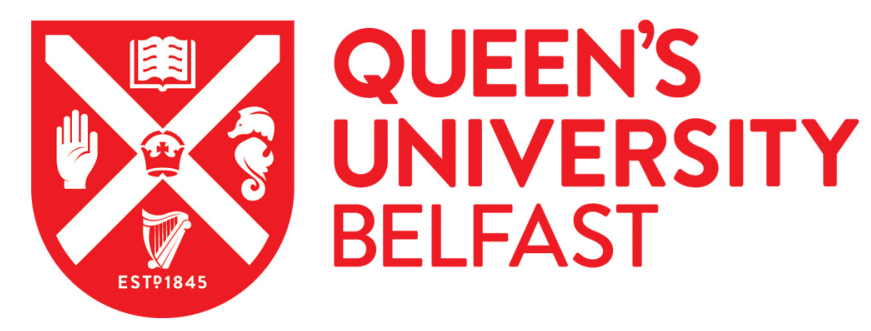

\title{
The mutagenesis of a single site for enhancing or reversing the enantio- or regiopreference of cyclohexanone monooxygenases
}

Hu, Y., Xu, W., Hui, C., Xu, J., Lin, X., Huang, M., \& Wu, Q. (2020). The mutagenesis of a single site for enhancing or reversing the enantio- or regiopreference of cyclohexanone monooxygenases. Chemical Communications, 56(65), 9356-9359. https://doi.org/10.1039/D0CC03721D

Published in:

Chemical Communications

Document Version:

Peer reviewed version

Queen's University Belfast - Research Portal:

Link to publication record in Queen's University Belfast Research Portal

Publisher rights

Copyright 2020 Royal Society of Chemistry. This work is made available online in accordance with the publisher's policies. Please refer to any applicable terms of use of the publisher.

\section{General rights}

Copyright for the publications made accessible via the Queen's University Belfast Research Portal is retained by the author(s) and / or other copyright owners and it is a condition of accessing these publications that users recognise and abide by the legal requirements associated with these rights.

Take down policy

The Research Portal is Queen's institutional repository that provides access to Queen's research output. Every effort has been made to ensure that content in the Research Portal does not infringe any person's rights, or applicable UK laws. If you discover content in the Research Portal that you believe breaches copyright or violates any law, please contact openaccess@qub.ac.uk. 


\section{ChemComm}

The Mutagenesis of a Single Site for Enhancing or Reversing the Enantio- or Regiopreference of Cyclohexanone

Monooxygenases

\begin{tabular}{|r|l|}
\hline Journal: & ChemComm \\
\hline Manuscript ID & CC-COM-05-2020-003721.R1 \\
\hline Article Type: & Communication \\
\hline \multicolumn{2}{l}{} \\
\hline
\end{tabular}

SCHOLARONE $^{m}$
Manuscripts 


\title{
Journal Name
}

\section{COMMUNICATION}

\section{The Mutagenesis of a Single Site for Enhancing or Reversing the Enantio- or Regiopreference of Cyclohexanone Monooxygenases}

Received 00th January 20xx, Accepted 00th January 20xx

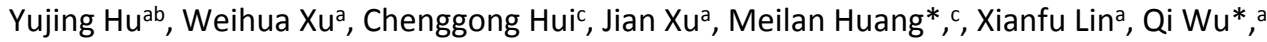

DOI: $10.1039 / \times 0 x \times 00000 x$

www.rsc.org/

The mutagenesis of a "second sphere" switch residue of $\mathrm{CHMO}_{\text {Acineto }}$ could control its enantio- and regiopreference. Replacing phenylalanine (F) at position 277 of $\mathrm{CHMO}_{\text {Acineto }}$ into larger tryptophan (W) enabled a significant enhancement of enantio- or regioselectivity toward structurally diverse substrates, moreover, a complete reversal of enantio- or regiopreference was realized by mutating $\mathrm{F} 277$ into a range of smaller amino acids (A/C/D/E/G/H/I/K/L/M/N/P/Q/R/S/T/V).

Directed evolution, as a method generally exploited to engineer the binding properties of proteins or the catalytic profiles of enzymes, has been utilized for manipulating their regio- or enantioselectivity, substrate scope and stability. ${ }^{1}$ However, huge screening efforts are still the bottleneck of directed evolution. One of efficient mutagenesis strategies is scrutinizing the potential sites for enzyme engineering to achieve the desired catalytic properties, which can significantly reduce the number of mutants to be investigated. Computational modeling and crystallography technique provide useful information on structures of enzymes and reaction mechanisms, and allow for the rational selection of potential residues to be mutated. In the past decade, enormous efforts in rational engineering of enzymes have been reported where the residues lining the binding pocket were selected smartly to tune the enzymatic properties. ${ }^{2}$ Generally, the selected residues were usually in direct contact with the substituents of substrates to reshape the binding pocket for the desired properties. However, several advances focusing on mutagenesis of the residues distant from substrate-binding sites for tuning enzymatic properties have also been reported. ${ }^{3}$ For example, a possible "second sphere" residue P440 of

\footnotetext{
a. Department of Chemistry, Zhejiang University, Hangzhou 310027 (China). E-mail: Ilc123@zju.edu.cn

b. College of Biotechnology and Pharmaceutical Engineering, Nanjing Tech University, Nanjing 211816, PR China

School of Chemistry and Chemical Engineering, Queen's University, Belfast, BT9 5AG (U.K.). E-mail: m.huang@qub.ac.uk

$\dagger$ Electronic Supplementary Information (ESI) available. See DOI: 10.1039/x0xx00000x
}

phenylacetone monooxygenase from Thermobifida fusca (PAMO) was mutated for transformation of several substituted cyclohexanone derivatives with high enantioselectivities. ${ }^{3 a}$ The mutation of Q93 and P94 of PAMO situated remote from the active site induced domain movements to reshape the binding pocket, leading to an expansion of the substrate scope. ${ }^{3 \mathrm{~b}}$

Cyclohexanone monooxygenases (CHMO, EC 1.14.13.22) belong to the subfamily of Baeyer-Villiger monooxygenases (BVMOs) and transform a multitude of reactions selectively. ${ }^{4}$ The reaction catalyzed by a $\mathrm{CHMO}$ generally forms a tetrahedral Criegee intermediate through a nucleophilic attack of the C4aperoxyflavin intermediate on the substrate carbonyl carbon, and then the rearrangement of the Criegee intermediate yields the ester or lactone product. ${ }^{5}$ Previous theoretical investigation reported that the insertion of an oxygen atom has a certain directionality due to the requirement of anti-periplanarity, as a result, the orientation of the substituent groups of ligands ultimately determines their enantioselectivity. ${ }^{6}$

Natural CHMOs often gave one specific enantio- or regiopreference toward an array of substrates. Recently, reversal of regio - or enantioselectivity of products was reported by engineering $\mathrm{CHMOs}$ from different sources, ${ }^{7-10}$ such as Acinetobacter sp NCIMB 9871 ( $\left.\mathrm{CHMO}_{\text {Acineto }}\right)^{7}$, Thermocrispum municipale $\left(\mathrm{CHMO}_{\text {Thermo }}\right)^{8}$, Arthrobacter sp. BP2 $\left(\mathrm{CHMO}_{\text {Arthro }}\right)^{9}$ and Acinetobacter calcoaceticus $\left(\mathrm{CHMO}_{\text {Acineto-cal }}\right)^{10}$. Notably, most studies were focused on mutating hot spots lining the binding pocket in apparently direct contact with the substrates, such as L143, P431-L435 and F505 (numbered in CHMO $_{\text {Acineto). }}$ ). Exploring distinct residues that are far away from the moststudied substrate-binding sites would open a new pathway to manipulate its enantio- or regiopreference of CHMOs.

Here, we found mutating a "second sphere" switch residue F277 of $\mathrm{CHMO}_{\text {Acineto }}$ could control the enantio- or regiopreference toward four-membered, five-membered, sixmembered cycloketones (Scheme 1), and even sulfides. Up to now, mutating only one residue $\mathrm{F} 277$ of $\mathrm{CHMO}_{\text {Acineto }}$ for regulating its regio- or enantiopreference toward an array of substrates, has never been reported. Furthermore, the know- 

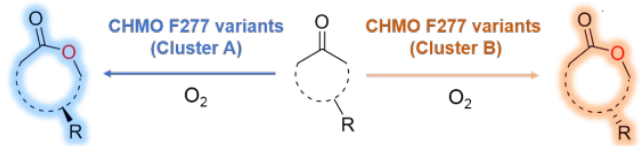

Scheme 1 Enantiocomplementary Baeyer-Villiger Oxidation of Various Cyclic Ketones.

-ledge obtained from $\mathrm{CHMO}_{\text {Acineto }}$ could be transferred to other CHMOs.

It is a big challenge to identify potential residues in an enzyme, mutagenesis of which could trigger a reversal of enantio- or regioselectivity with a reshaped binding pocket. $\mathrm{CHMO}_{\text {Acineto }}{ }^{7,11}$ was selected as a starting enzyme. Previous experimental results revealed that WT PAMO exhibits different catalytic properties in some cases from $\mathrm{CHMO}$, such as opposite stereopreference toward a same substrate. ${ }^{7 \mathrm{~g}, 13}$ Comparison of the structures of $\mathrm{CHMO}^{12 a}$, 12d and PAMO ${ }^{12 e}$ (Fig. S1), disclosed a small bulge at F277 connecting helix 260-276 and helix 278283 (numbered in $\mathrm{CHMO}_{\text {Acineto }}$ ) in $\mathrm{CHMO}$, while the bulge is absent in PAMO. Considering that the structural difference of enzymes is undoubtedly responsible for the specificity of substrates, we were curious to test position F277, since mutagenesis of this residue may modulate the properties of CHMO. It should be noted that the slight bulging at F277 is located at the entrance of a compact ligand-binding site composed of L143, L144, F246, F277, R327, L426, P428, F432, T433, L435, W490, F505, and is in proximity to the catalytic center (Fig. S2). The residue F277 forms a $\pi-\pi$ stacking interaction with the side chain of F246 and a cation- $\pi$ interaction with R327 that participates in the stabilization of the Criegee intermediate as well as in shifting throughout the catalytic cycle to accommodate NADPH binding ${ }^{12 a-12 b}$. Inspired by this, we speculated that mutating the bulky phenyl side chain of F277 into smaller sized ones may induce the reshaping of the binding pocket, which only allows one specific configuration of substrates to reach the proximity of the flavin, thus altering the enantio-preference or catalytic activity of this enzyme.

To gain a deep insight into the effect of position 277 on the catalytic properties, saturation mutagenesis at F277 was performed. 3-phenylcyclobutan-1-one 1a (Fig. 1) was selected as a model substrate, since $1 \mathbf{1}$ has a four-membered ring and the reversal of enantioselectivity by protein engineering for such a small cyclic non-natural substrate with high ring strain was never realized. As shown in Fig. 1 and Table S2, modest stereoselectivity was observed in the oxidation of 1a by WT $\mathrm{CHMO}_{\text {Acineto, }}$ which gave $R$ product with $60 \%$ ee. Strikingly, mutation of phenylalanine (F) at 277 into larger-sized tryptophan (W) enabled the enhanced enantioselectivity up to 99\% ee $(R)$ (WT, F277W classified into Cluster A). It is noteworthy that mutating $\mathrm{F} 277$ into all smaller-sized amino acids (F277A/C/D/E/G/H/I/K/L/M/N/P/O/R/S/T/V classified into Cluster $\mathrm{B}$ ) led to a distinct reversal of enantioselectivity in the conversion of 1 a (up to $97 \%$ ee (S)). The catalytic efficiency of mutants, determined by kinetic parameters (Table S3), was still retained relative to WT. To verify the potential application of these mutants in synthetic chemistry, we also performed the amplified reactions using $0.5 \mathrm{~L}$ cell culture and $2.9 \mathrm{~g} / \mathrm{L}$ of $1 \mathrm{a}$. Both WT $\mathrm{CHMO}_{\text {Acineto }}$ and $\mathrm{F} 277 \mathrm{~W}$ achieved complete conversions

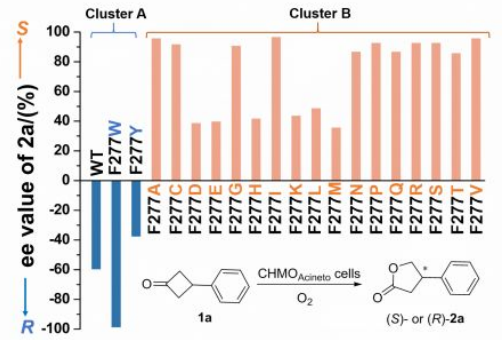

Fig. 1 Enantioselectivity of WT $\mathrm{CHMO}_{\text {Acineto }}$ and its mutants in the oxidation of ketone 1a.

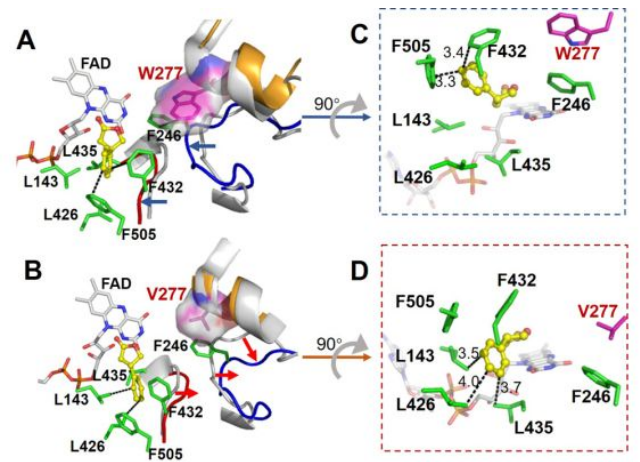

Fig. 2 Comparison of MD structures of WT CHMO and its mutants. (A) F277W complexed with (R)-2a; (B) F277V complexed with (S)-2a; (C), (D) A rotation about 90 degrees into the page from the perspective of $(A),(B)$. WT is shown with pale gray cartoon as a reference; Ligand $2 \mathrm{a}$ is shown with ball and sticks (yellow carbon atoms); The crucial position 277 is shown with sticks and surface. The unit of distances is in $\AA$.

toward 1a, and mutant F277V showed $85 \%$ conversion, providing similar stereoselectivity as analytical grade reactions. To our knowledge, F277W and F277V are by far the best biocatalysts with the highest enantiopreference for offering $(R)$ and (S)-2a among all BVMOs reported.

To understand the source of distinctly enhanced and reversed enantioselectivity, molecular dynamics (MD) simulations were performed. It was found that the substituent groups of ligands do not form direct contact with position 277 (Fig. 2). Considering the orientation of the substituent groups of ligands determines the enantioselectivity ${ }^{6}$, it is demanding to find out how the orientation of the substituent groups is affected by protein environment. Careful inspection of the structures, disclosed that the side chain of W277 still forms a $\pi-\pi$ stacking interaction with F246, while F277 was mutated into V, the corresponding $\pi-\pi$ stacking interaction was lost. Notably, loop 243-247 (in blue) adjacent to loop 431-435 (in red) was concomitantly moved (Fig. 2A\&B). As a result, loop 431-435 (in red), which was suggested to be a selectivity-controlled region $^{7 a}, 7 c, 7 e, 8 a-8 b$, may be induced to move inward into or outward from the binding pocket (Fig. 2A\&B). (S)-2a with a "down" substituent may be hampered by the steric effect introduced by the inward movement of loop 431-435; in contrast, the prefered $(R)$-2a with an "up" substituent forms the interaction with the side chain of F432 and F505, thus resulting in an enhanced enantioselectivity of (R)-2a (Fig. 2A). Since $\mathrm{CH}-\pi$ hydrogen bonds between the $\mathrm{Ph}$ substituent and the side chain of L143, L426 and L435 may be formed in the reshaped protein environment, (S)-2a would be more energically preferred, thus resulting in enhanced (S)-selectivity of 2 a (Fig. 2B). It could be 
speculated that position 277 may act as a "second sphere" switch residue, mutagenesis of which could cause the concomitant movement of adjacent loops, and induce the reshaping of binding pocket (Fig. S4), so as to control the preference of specific stereo- or regio-isomers of products.

Next, to explore the catalytic potential of enzymes, the stereoselectivity-enhanced mutant (F277W) and three selected stereoselectivity-reversed mutants (F277P/V/I) evolved for 1a were tested in the oxidation of various substrates including fivemembered cycloketones (3a), six-membered cycloketones (1 $\mathbf{b}$ 1I, 3b-3c) and sulfides (6a-6c) (Scheme 2).

In the desymmetrization of prochiral substrates (1b-1f), F277W gave the corresponding products with enhanced ee values (up to $>99 \%$ ) in comparison to WT (Table 1). In particular for 1e, ee value up to $99 \%$ (-) was obtained by F277W, while only $33 \%(+)$ by WT. Strikingly, the single-site mutants (F277P/V/I) completely reversed the stereopreference in the transformation of almost all tested substrates except $\mathbf{1 b} \mathbf{b}-\mathbf{1 c}$ with small methyl or ethyl group (Table 1 ).

We further evaluated the interesting influence of F277 switch on the regioselectivity in the conversion of asymmetric ketones. WT only exhibited moderate regio- and stereoselectivity toward $\mathbf{3 a}$ to yield the corresponding mixture of lactone products $4 \mathbf{a}$ and $\mathbf{5 a}\left(\mathbf{4} \mathbf{a} / \mathbf{5} \mathbf{a}=82 / 18, e_{4 a} 87 \%(R)\right)$ (Table 2$)$. It is undoubtedly a challenge to override traditional electronic effects for switching regioselectivity from normal products to abnormal products. In sharp contrast, the single-site mutants F277P/V/I enabled the complete switch of regiopreference, leading to the dominated products $5 \mathbf{a}\left(\mathbf{4 a} / \mathbf{5 a}<5 / 95\right.$, ee $\left._{\mathbf{5}}>\mathbf{9 6 \%}(S)\right)$ with high ee values. Similar results with completely reversed regioselectivity and enhanced stereoselectivity displayed by F277P/V/I mutants were also observed for $\mathbf{3 c}$ (Table 2). These results implied clearly the important role of selectivity "switch" of F277. Interestingly, in the kinetic resolution of 2-phenyl cyclohexanone $\mathbf{3 b}$ by mutants F277P/V/I, high stereopreference was still retained as WT $\left(\mathbf{4 b} / \mathbf{5 b}>99 / 1, \mathrm{ee}_{4 \mathrm{~b}}>95 \%(R)\right)$.

The regulation of stereoselectivity in the sulfoxidation of sulfides by using F277 mutants was also investigated (Table S4). A reversal in enantioselectivity toward $\mathbf{6} \mathbf{a}$ and $\mathbf{6 b}$ was achieved by F277P/V/I (Table S4, entries 1-8). For substrate 6c, compared with $\mathrm{WT}$, the decreased $\mathrm{ee}_{\mathrm{p}}$ value of product $7 \mathrm{c}$ also implied an increased tendency of the reversed enantio-preference toward (S)-7c by F277P/V/I, though the enantioselectivity was not reversed (Table S4, entries 9-12). The results revealed that mutagenesis of the single site 277 can manipulate the selectivity for various structurally diverse substrates.

After demonstrating the stereoselectivity-"switch" role played by $\mathrm{F} 277$ of $\mathrm{CHMO}_{\text {Acineto, }}$ we next turned to extend the generality of our approach in other $\mathrm{CHMOs.} \mathrm{Multiple-sequence}$ alignment of $\mathrm{CHMO}_{\text {Acineto }}$ with 94 homologues revealed that the residue $\mathrm{F} 277$ exhibited high conservation (Fig. S5). $\mathrm{CHMO}_{\text {Thermo, }}$ $\mathrm{CHMO}_{\text {Rhodo, }}$ and CHMO from Rhodococcus sp. HI-31(chnb2) $\left(\mathrm{CHMO}_{\text {Rhodo2 }}\right)$ were selected as targets (Fig. S6). Phenylalanine (F) at the corresponding position of CHMOs was mutated into larger-sized tryptophan (W) and smaller-sized valine (V), isoleucine (I) and proline (P). The stereocontrolled experiments catalyzed by corresponding mutants were carried out using 1a-
Table 1 Desymmetrization of ketones $1 \mathrm{a}-1 \mathbf{1}$ by WT $\mathrm{CHMO}_{\text {Acineto }}$ and variants ${ }^{a}$.

\begin{tabular}{|c|c|c|c|c|c|c|}
\hline \multirow[b]{2}{*}{ Enzyme } & $1 \mathrm{~b}-\mathrm{I}$ & $\underset{\mathrm{O}_{2}}{\stackrel{\mathrm{HMO}_{\text {Acineto }} \text { cells }}{\longrightarrow}}$ & $(S)$ - or $(R)-2 \mathrm{~b}-1$ & \multirow[t]{2}{*}{$\begin{array}{l}\text { b } R=M e \\
\text { c } R=E t \\
\text { d } R=n-P r \\
\text { e } R=n \text {-Penty } \\
\text { f } R=P h\end{array}$} & \multicolumn{2}{|c|}{$\begin{aligned} \text { g } \mathrm{R}=3-\mathrm{MeC}_{6} \mathrm{H}_{4} \\
\text { h } \mathrm{R}=4-\mathrm{MeC}_{6} \mathrm{H}_{4} \\
\text { i } \mathrm{R}=3-\mathrm{FC}_{6} \mathrm{H}_{4} \\
\text { yl } \mathrm{j} R=4-\mathrm{FC}_{6} \mathrm{H}_{4} \\
\text { k } \mathrm{R}=4-\mathrm{CH}_{3} \mathrm{OC}_{6} \mathrm{H}_{4} \\
\text { l } \mathrm{R}=4-\mathrm{ClC}_{6} \mathrm{H}_{4}\end{aligned}$} \\
\hline & 1a & 1b & 1c & & $1 e$ & $1 f$ \\
\hline WT & $99^{b}, 62^{c}(R)^{d}$ & $99,99(S)$ & $99,98(S)$ & $99,94(S)$ & $89,33(+)^{e}$ & $99,98(S)$ \\
\hline F277W & $99,99(R)$ & $99,99(S)$ & $99,99(S)$ & $99,97(S)$ & $50,99(-)$ & $68,99(S)$ \\
\hline F277P & $99,93(S)$ & $99,99(S)$ & $99,94(S)$ & $99,88(R)$ & $84,97(+)$ & $99,97(R)$ \\
\hline F277V & $99,96(S)$ & $99,99(S)$ & $99,78(S)$ & $99,98(R)$ & $81,99(+)$ & $99,99(R)$ \\
\hline F277I & $99,97(S)$ & $99,92(S)$ & $99,94(S)$ & $99,91(R)$ & $79,99(+)$ & $99,98(R)$ \\
\hline Enzyme & $1 \mathrm{~g}$ & $1 \mathrm{~h}$ & $1 \mathbf{i}$ & $1 j$ & $1 k$ & 11 \\
\hline WT & $79,88(-)$ & $87,97(-)$ & $81,96(-)$ & $84,93(-)$ & $88,60(-)$ & $91,85(-)$ \\
\hline F277P & $91,93(+)$ & $92,96(+)$ & $93,99(+)$ & $93,99(+)$ & $86,99(+)$ & $97,99(+)$ \\
\hline F277V & $93,98(+)$ & $95,96(+)$ & $91,99(+)$ & $90,87(+)$ & $91,99(+)$ & $99,99(+)$ \\
\hline F277I & $84,89(+)$ & $85,95(+)$ & $89,99(+)$ & $95,99(+)$ & $83,99(+)$ & $90,99(+)$ \\
\hline
\end{tabular}

$a$ The whole cell experiments are described in Experimental section. ${ }^{b}$ The conversion was determined by HPLC or GC. ${ }^{c}$ ee values of lactones were calculated by HPLC data or GC data. ${ }^{d}$ The absolute configurations of lactones were confirmed by comparison with the literature ${ }^{14} .{ }^{e}$ The optical rotations.

Table 2 Oxidative kinetic resolution of ketones rac-3a-3c by WT $\mathrm{CHMO}_{\text {Acineto }}$ and variants $^{a}$.

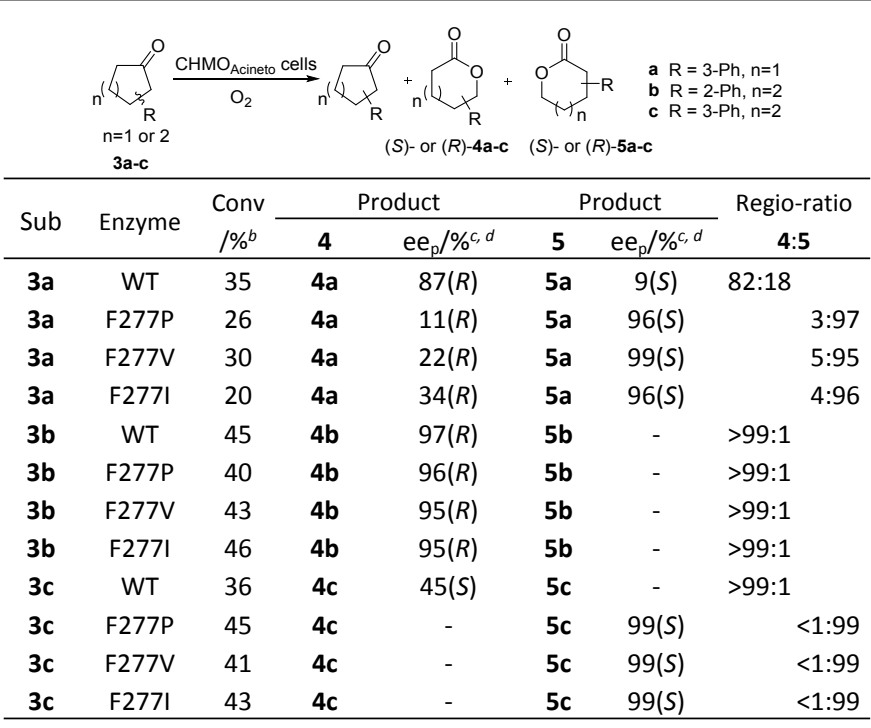

${ }^{a}$ The whole cell experiments are described in Experimental section. ${ }^{b, c}$ Calculated by HPLC data. ${ }^{d}$ The absolute configurations of lactones were confirmed by comparison with the literature ${ }^{14}$.

$$
\text { Scheme } 2 \text { The sulfoxidation of sulfides. }
$$

1f as substrates (Table 3 and Table S5). As expected, in the conversion of 1a, 1d-1f with medium- or large-sized substituents, all CHMOs mutants displayed highly enhanced or reversed enantioselectivities. These results implied that this stereoselectivity-"switch" role of $\mathrm{F} 277\left(\mathrm{CHMO}_{\text {Acineto }}\right)$ may be generally used for engineering other CHMOs that share sequences similarity to $\mathrm{CHMO}_{\text {Acineto }}$. Moreover, it is usually very 
Table 3 Baeyer-Villiger oxidation of ketones $\mathbf{1 a - 1}$ by WT CHMOs and variants ${ }^{a, b}$.

\begin{tabular}{cccccccc} 
CHMO & Enzyme & 1a & 1b & 1c & 1d & 1e & 1f \\
\hline \multirow{6}{*}{ CHMO } & WT & $51(R)$ & $99(S)$ & $99(S)$ & $94(S)$ & $34(-)$ & $89(S)$ \\
Thermo & F279W & $98(R)$ & $99(S)$ & $99(S)$ & $97(S)$ & $99(-)$ & $98(S)$ \\
& F279V & $94(S)$ & $99(S)$ & $74(S)$ & $96(R)$ & $93(+)$ & $98(R)$ \\
& F279I & $95(S)$ & $99(S)$ & $50(S)$ & $98(R)$ & $94(+)$ & $98(R)$ \\
\hline \multirow{6}{*}{ CHMO } & WT & $34(R)$ & $99(S)$ & $98(S)$ & $74(S)$ & $21(+)$ & $15(S)$ \\
& F279W & $89(R)$ & $99(S)$ & $99(S)$ & $98(S)$ & $99(-)$ & $99(S)$ \\
& F279P & $97(S)$ & $98(S)$ & $47(S)$ & $98(R)$ & $99(+)$ & $99(R)$ \\
& F279V & $96(S)$ & $97(S)$ & $34(S)$ & $94(R)$ & $99(+)$ & $98(R)$ \\
& F279I & $95(S)$ & $98(S)$ & $20(S)$ & $94(R)$ & $99(+)$ & $98(R)$ \\
\hline \multirow{4}{*}{ CHMO } & F282W & $96(R)$ & $99(S)$ & $99(S)$ & $98(S)$ & $33(-)$ & $95(S)$ \\
Rhodo2 & F282P & $91(S)$ & $94(S)$ & $80(R)$ & $99(R)$ & $99(+)$ & $94(R)$ \\
& F282V & $94(S)$ & $94(S)$ & $84(R)$ & $99(R)$ & $99(+)$ & $96(R)$ \\
& F282I & $88(S)$ & $94(S)$ & $73(R)$ & $99(R)$ & $99(+)$ & $84(R)$ \\
\hline
\end{tabular}

challenging to reverse the enantioselectivity in the conversion of small-sized substrates by mutating only a single site, such as 1b and 1c. Remarkably, for 1c with a small ethyl group, we found the reversal of enantioselectivity was achieved by $\mathrm{CHMO}_{\text {Rhodo2 }}$ from ee value of $99 \%(S)(\mathrm{WT})$ to $84 \%(R)$, other $\mathrm{CHMO}$ variants from different species also gave an increased ratio of $(R)$-products in comparison to WT. In the future, the mutation of F277 combined with other known active sites (e.g. L143, P431-L435 and F505) would be implemented to verify if there are any cooperative or additive effects for the reversal of enantioselectivity toward substrates with small substituents.

In conclusion, the "designed" directed evolution of enzymes is usually focused on the mutation of ligand-binding sites, especially the sites in direct contact with the substituents of ligands. Here we discovered that a "second sphere" site of enzymes acts as a stereo- and regiocontrolled switch, mutagenesis of which may induce the reshaping of active sites so as to tune the preference of chiral products. Furthermore, the knowledge obtained from engineering $\mathrm{CHMO}_{\text {Acineto }}$ could be efficiently transferred to other CHMOs.

The financial support from National Natural Science Foundation of China (91956128) and Natural Science Foundation of Zhejiang province (LY19B020014) are gratefully acknowledged.

\section{Conflicts of interest}

There are no conflicts to declare.

\section{Notes and references}

1 Selected reviews of directed evolution: (a) A. Currin, N. Swainston, P. J. Day and D. B. Kell, Chem. Soc. Rev., 2015, 44, 1172; (b) H. Renata, Z. J. Wang and F. H. Arnold, Angew. Chem., Int. Ed., 2015, 54, 3351; (c) N. J. Turner, Nat. Chem. Biol., 2009, 5, 567; (d) C. Zeymer and D. Hilvert, Annu. Rev. Biochem., 2018, 87, 131; (e) G. Qu, A. Li, C. G. Acevedo-Rocha, Z. Sun, M. T. Reetz, Angew. Chem., Int. Ed., 2020, DOI: 10.1002/anie.201901491.

2 (a) W. P. Dijkman, C. Binda, M. W. Fraaije and A. Mattevi, ACS Catal., 2015, 5, 1833; (b) X. D. Kong, Q. Ma, J. Zhou, B. B. Zeng and J. H. Xu, Angew. Chem., Int. Ed., 2014, 53, 6641; (c) A. O.
Magnusson, M. Takwa, A. Hamberg and K. Hult, Angew. Chem., Int. Ed., 2005, 44, 4582; (d) J. Xu, Y. Cen, W. Singh, J. Fan, L. Wu, X. Lin, J. Zhou, M. Huang, M. T. Reetz and Q. Wu, J. Am. Chem. Soc., 2019, 141, 7934.

3 (a) M. T. Reetz and S. Wu, J. Am. Chem. Soc., 2009, 131, 15424; (b) S. Wu, J. P. Acevedo, M. T. Reetz, Proc. Natl. Acad. Sci. U. S. A., 2010, 107, 2775.

4 (a) K. Balke, A. Beier and U. T. Bornscheuer, Biotechnol. Adv., 2018, 36, 247; (b) M. J. Fürst, A. Gran-Scheuch, F. S. Aalbers and M. W. Fraaije, ACS Catal., 2019, 9, 11207; (c) J. Dong, E. Fernandez-Fueyo, F. Hollmann, C. E. Paul, M. Pesic, S. Schmidt, Y. Wang, S. Younes and W. Zhang, Angew. Chem., Int. Ed., 2018, 57, 9238; (d) D. Holtmann, M. W. Fraaije, I. W. Arends, D. J. Opperman and F. Hollmann, Chem. Commun., 2014, 50, 13180; (e) S. Schmidt, K. Castiglione and R. Kourist, Chemistry, 2018, 24, 1755; (f) J. B. Wang, G. Li and M. T. Reetz, Chem. Commun., 2017, 53, 3916.

5 D. Sheng, D. P. Ballou and V. Massey, Biochemistry, 2001, 40, 11156.

6 (a) I. Polyak, M. T. Reetz and W. Thiel, J. Am. Chem. Soc., 2012, 134, 2732; (b) I. Polyak, M. T. Reetz and W. Thiel, J. Phys. Chem. B, 2013, 117, 4993.

7 (a) M. T. Reetz, B. Brunner, T. Schneider, F. Schulz, C. M. Clouthier and M. M. Kayser, Angew. Chem., Int. Ed., 2004, 43, 4075; (b) M. D. Mihovilovic, F. Rudroff, A. Winninger, T. Schneider, F. Schulz and M. T. Reetz, Org. Lett., 2006, 8, 1221; (c) Z.-G. Zhang, G.-D. Roiban, J. P. Acevedo, I. Polyak and M. T. Reetz, Adv. Synth. Catal., 2013, 355, 99; (d) C. M. Clouthier, M. M. Kayser and M. T. Reetz, J. Org. Chem., 2006, 71, 8431; (e) Y. Hu, J. Wang, Y. Cen, H. Zheng, M. Huang, X. Lin and Q. $\mathrm{Wu}$, Chem. Commun., 2019, 55, 2198; (f) M. T. Reetz, F. Daligault, B. Brunner, H. Hinrichs and A. Deege, Angew. Chem., Int. Ed., 2004, 43, 4078.

8 (a) G. Li, M. Furst, H. R. Mansouri, A. K. Ressmann, A. Ilie, F. Rudroff, M. D. Mihovilovic, M. W. Fraaije and M. T. Reetz, Org. Biomol. Chem., 2017, 15, 9824; (b) G. Li, M. Garcia-Borras, M. Furst, A. Ilie, M. W. Fraaije, K. N. Houk and M. T. Reetz, J. Am. Chem. Soc., 2018, 140, 10464; (c) M. J. L. J. Fürst, E. Romero, J. R. Gómez Castellanos, M. W. Fraaije and A. Mattevi, ACS Catal., 2018, 8, 11648.

9 (a) K. Balke, M. Baumgen and U. T. Bornscheuer, Chembiochem, 2017, 18, 1627; (b) K. Balke, S. Schmidt, M. Genz and U. T. Bornscheuer, ACS. Chem. Biol., 2016, 11, 38.

10 (a) H. L. van Beek, E. Romero and M. W. Fraaije, ACS Chem. Biol., 2017, 12, 291; (b) Y. Zhang, Y.-Q. Wu, N. Xu, Q. Zhao, H.L. Yu, J.-H. Xu, ACS Sustain. Chem. Eng., 2019, 7, 7218.

11 C. T. Walsh and Y.-C. J. Chen, Angew. Chem., Int. Ed., 1988, 27, 333.

12 (a) E. Romero, J. R. G. Castellanos, A. Mattevi and M. W. Fraaije, Angew. Chem., Int. Ed., 2016, 55, 15852; (b) I. A. Mirza, B. J. Yachnin, S. Wang, S. Grosse, H. Bergeron, A. Imura, H. Iwaki, Y. Hasegawa, P. C. K. Lau and A. M. Berghuis, J. Am. Chem. Soc., 2009, 131, 8848; (c) B. J. Yachnin, T. Sprules, M. B. McEvoy, P. C. K. Lau and A. M.Berghuis, J. Am. Chem. Soc., 2012, 134, 7788; (d) B. J. Yachnin, M. B. McEvoy, R. J. D. MacCuish, K. L. Morley, P. C. K. Lau and A. M. Berghuis, ACS Chem. Biol., 2014, 9, 2843; (e) R. Orru, H. M. Dudek, C. Martinoli, D. E. Torres Pazmino, A. Royant, M. Weik, M. W. Fraaije and A. Mattevi, J. Biol. Chem., 2011, 286, 29284-29291.

13 Z. G. Zhang, R. Lonsdale, J. Sanchis and M. T. Reetz, J. Am. Chem. Soc., 2014, 136, 17262.

14 (a) L. Zhou, X. Liu, J. Ji, Y. Zhang, X. Hu, L. Lin and X. Feng, J. Am. Chem. Soc., 2012, 134, 17023; (b) M. J. Taschner, D. J. Black and Q. Z. Chen, Tetrahedron: Asymmetry, 1993, 4, 1387; (c) W. Wu, W. Cao, L. Hu, Z. Su, X. Liu and X. Feng, Chem. Sci., 2019, 10, 7003; (d) M. Ogasawara, Y. Tseng, S. Arae, T. Morita, T. Nakaya, W. Wu and K. Kamikawa, J. Am. Chem. Soc., 2014, 136, 9377. 